\title{
Managing the Disruption of Mobility Services: How to align the value propositions of key ecosystem players Joel Wolff and Esko Hakanen
}

\author{
" Over the past 20 years we've gotten very good at predicting whether a major \\ new technology will supplant an older one-but we are still terrible at \\ predicting when that substitution will take place. "
}

Ron Adner \& Rahul Kapoor (2016)

\begin{abstract}
Many industries nowadays are facing drastic changes that enable and require new forms of interdependencies that facilitate complex ecosystems of interconnected actors. This paper investigates such a transformation facing the mobility sector, as user-centric bundles of mobility services are being introduced and compiled, by referring to the Mobility-as-a-Service (MaaS) concept. In the process, new value propositions arise that call for aligning the established players with new entrants. The implementation of MaaS is still in its infancy, and many open questions remain about how local authorities should support its emergence. One key challenge relates to decomposing the focal offering of the MaaS ecosystem into complementary value propositions for key players in the industry. This paper presents the results of a constructive design research project, building on interviews with a leading MaaS provider, as well as stakeholders representing national and local authorities in four European cities. The findings emphasize the need to balance a shared desire to disrupt conventional ways of offering mobility services against reluctance to overturn the industry's public and private incumbents. The co-design framework that results serves to summarize five steps that enable MaaS by guiding strategic interaction between local authorities and various players in the mobility ecosystem. In addition, the article builds on ecosystem research insights and emphasizes the need to align value propositions among multiple stakeholders. The study suggests that the mobility sector provides a prominent empirical context for future ecosystem research.
\end{abstract}

\section{Introduction}

The mobility sector is one of the industry sectors that faces growing pressure to adapt to a changing society by implementing new solutions. Factors such as urbanization, digitalization, and climate change have led to increasing political and social demands for new means to develop automotive technology, rethink the established mobility solutions, and reduce emissions. For example, the European Commission declared their commitment to address these challenges and achieve more sustainable mobility and transport by boosting multimodal transport in the European Green Deal (European Commission, 2019). A key component in this transformation is the concept of Mobility-as-a-Service
(MaaS), which is expected to substitute conventional mobility services with more efficient, resilient, and less polluting technologies (Smith et al., 2020). MaaS has become an umbrella term for a bundle of services that grant users "access to a range of mobility services including public transport and commercial services such as car hire or taxi" (Pangbourne et al., 2020). While the overall concept is widely appreciated and expected to scale rapidly, many questions remain about how MaaS should be governed, and how policies and regulations may be utilized for desired results.

The underlying premise of MaaS is enticing, albeit challenging. One can argue that offering personal mobility as a modular service follows a similar line of 


\section{Managing the Disruption of Mobility Services: How to align the value propositions of key ecosystem players Joel Wolff and Esko Hakanen}

development as where a specific functionality is provided as a scalable service. People and firms rely on such offerings for music or video streaming (for example, Spotify or Netflix), telecom access, or cloud computing (Venters \& Whitley, 2012), and even for demanding industrial solutions; a famous example being Rolls-Royce's power-by-the-hour concept (Neely, 2008). However, these previous examples often relied on the actions of one focal operator. In turn, MaaS implementation may prove to be considerably more challenging in operation, as the envisioned service bundle relies on multiple components, which are produced, controlled, and offered by different providers. Moreover, the forerunners of MaaS likely need investments that may turn into enabling technologies for later, more profitable complementary offerings (see Teece, 2018). Similar to the telecom market, where wireless networks have surpassed traditional landline services, the end-user may remain completely oblivious about the intricate processes and infrastructures that are enabling the current transformation.

The focal value proposition of MaaS relies on investments in complementary offerings, along with modular interaction between independent organizations without full hierarchical control. Shaped by a common focal offering, MaaS essentially defines an ecosystem (Adner, 2017; Jacobides et al., 2018; Kapoor, 2018; Shipilov \& Gawer, 2020). To realize the focal offering requires several mutually supporting, firm-level value propositions (VPs) among diverse stakeholders that need to be aligned in a way that supports the overall ecosystem objective (Eggert et al., 2018; Bailetti et al., 2020).

The mobility market is populated and regulated by local or national authorities that might hope for the emergence of a MaaS ecosystem, but which are at the same time adamant that new entrants will not disrupt their continuing role or power. This duality can cause confusion among local authorities concerning the correct regulative policies or rules for enabling MaaS. While parties may agree on the focal offering of MaaS as a more user-friendly, adaptable personal mobility solution that will augment or even replace the current, state-controlled public transportation services, no agreement has yet been reached on who should lead the disruption of urban mobility or what rules should mediate the process. Since prior successes in managing disruptions are rare (Gans, 2016), it remains unknown how to balance the consequences of opening the market while at the same time coping with the conflicting interests it generates. Thus, the objective of this paper is to investigate how to manage the disruption of an ecosystem by aligning its new focal offering with the value propositions of conventional market players.

This study provides a threefold contribution. First, the paper clarifies the emerging concept of MaaS by focusing on its focal offering to the end user and role in aligning complementary VPs based on various modular components. Second, it presents a co-design framework to guide local authorities when implementing MaaS, providing a starting point for developing, designing, and facilitating MaaS solutions in local contexts. Third, the article contributes to the emerging ecosystem literature with an illustrative example of how an ecosystem's focal offering (Adner, 2017; Kapoor, 2018) relies on aligning the contributions of multiple external stakeholders (Bailetti et al., 2020), and also demonstrates why the MaaS concept can provide a particularly fertile ground for advancing ecosystem research.

The paper consists of four sections. First, we present the study's conceptual background with a specific emphasis on clarifying the MaaS concept and its impact as a disruptor of conventional mobility services. Then we present the study's methodological approach. Next, the findings section demonstrates the co-design process, its stages and outcomes, to clarify the path for creating the MaaS co-design framework. Last, the paper demonstrates the relevance of the framework and discusses the overall contribution to theoretical discussions underlying the study.

\section{Theoretical insights from existing literature}

This paper's theoretical foundation builds on the intersection of three topics: ecosystems, disruptive innovation, and socio-technical system design. First, we present the principles of ecosystem research, focusing on disruptive innovation and the role of value propositions in this context. Then, we address the key principles of MaaS, contrasting the concept with more conventional approaches to mobility services. Last, we explore the challenges of designing a controlled disruption of a mobility ecosystem.

\section{Disruptive innovation in an ecosystem context}

We view the starting point of an ecosystem as a focal 


\section{Managing the Disruption of Mobility Services: How to align the value propositions of key ecosystem players Joel Wolff and Esko Hakanen}

offering that is co-developed by a group of actors who have become bound together by the nonredeployability of their collective investments (Adner, 2017; Jacobides et al., 2018; Shipilov \& Gawer, 2020). In contrast with more traditional organizational networks and alliances, ecosystems do not rely on formal agreements or collaboration structures, but rather build on complementary offerings and symbiotic relationships (Kapoor, 2018; Shipilov \& Gawer, 2020). The focal offering is often rather abstract, increasing the need for more explicit descriptions that outline the ecosystem's VP and benefits for individual stakeholders (Bailetti et al., 2020). Ecosystems are open for competition and, thus, technological development may see old and new solutions rivaling head-to-head in the same environment (Adner \& Kapoor, 2016). If and when a new technology can surpass the previous one seems to depend on complex tradeoffs and competitive dynamics regarding, for example, the ecosystem's emergence versus extension (Adner \& Kapoor, 2016), gaining support from complementary providers (Ozalp et al., 2018), or lower price versus higher quality (Christensen et al., 2015). However, starting from Moore's seminal article (1993), ecosystem research has implied a trend that could change or surpass existing means of conducting business (Jacobides et al., 2018; Ozalp et al., 2018; Rajala et al., 2018), potentially disrupting any industry.

According to Christensen's original definition, the VP of a disruptive innovation targets low-end user groups (whom industry incumbents have neglected). It is driven by a new entrant with smaller resources, which gradually advances as the new alternative begins to reach the mainstream customers (Christensen et al., 2015; Christensen, 1997). Disruptive firms often introduce new actors and reconfigure existing activities (Amit \& Zott, 2012), producing an unprecedented offering compared to industry incumbents. The disruptor's actions can also spark newfound resilience and performance improvements among incumbents, leading to a long period of coexistence between the new and old technologies (Adner \& Kapoor, 2016). Thus, a central task during ecosystem disruption is to reduce uncertainty between various participants by clarifying strategies and actions for adapting to the disruption (Eggert et al., 2018; Snihur et al., 2018; Bailetti et al., 2020). The complexities, dynamics, nested hierarchies, and interdependencies of an ecosystem (Massa et al., 2018) limit the understanding of potential disruptions. For example, it remains unclear what the specific activities are, and who the actors are that will become disrupted in MaaS development (see Gans, 2016).

\section{The value proposition of MaaS in urban mobility ecosystems}

It is frequently implied that MaaS solutions will disrupt the mobility market and facilitate a new mobility ecosystem (Hensher et al., 2020). The flexibility of usercentric personal mobility solutions, which are often seen as the fundamental value proposition of MaaS, offer multiple long-term benefits: for example, decreasing the need for privately owned vehicles, alleviating traffic congestion, and reducing greenhouse gas emissions (MaaS Alliance, 2017; Hensher et al., 2020). MaaS solutions rely on technological innovations that enable more user-friendly interfaces to access, find, and combine different transport services into a comprehensive, intelligent mobility service system (Heikkilä, 2014; MaaS Alliance, 2017). The MaaS ecosystem depends on an array of separate groups of actors, including local authorities, transport, and infrastructure providers, who all work to fulfill part of what is needed for MaaS services to function effectively (Arias-Molinares \& García-Palomares, 2020; Hensher et al., 2020). Thus, a considerable challenge exists for aligning VPs among multiple stakeholders that contribute to the value creation process (Eggert et al., 2018; Bailetti et al., 2020)

The envisioned MaaS solutions differ in many ways from conventional approaches for offering mobility services and thus require authorities to consider regulatory policies. Figure 1 illustrates how these differences are manifested in the user VP, focusing on the "communication of an organization's ability to share resources and offer a superior value package to targeted customer" (Payne et al., 2017). On the left-hand side, conventional mobility services often benefit from a clear division of roles and responsibilities, highlighting the mobility provider's role. For example, suppose a railroad company operating trains defines the available services and sells tickets via their ticketing booths to these lines. In that case, the customer may interact with only one company for their trip (illustrated in yellow on the lefthand side). Essentially, the VP of a conventional mobility 


\section{Managing the Disruption of Mobility Services: How to align the value propositions of key ecosystem players Joel Wolff and Esko Hakanen}

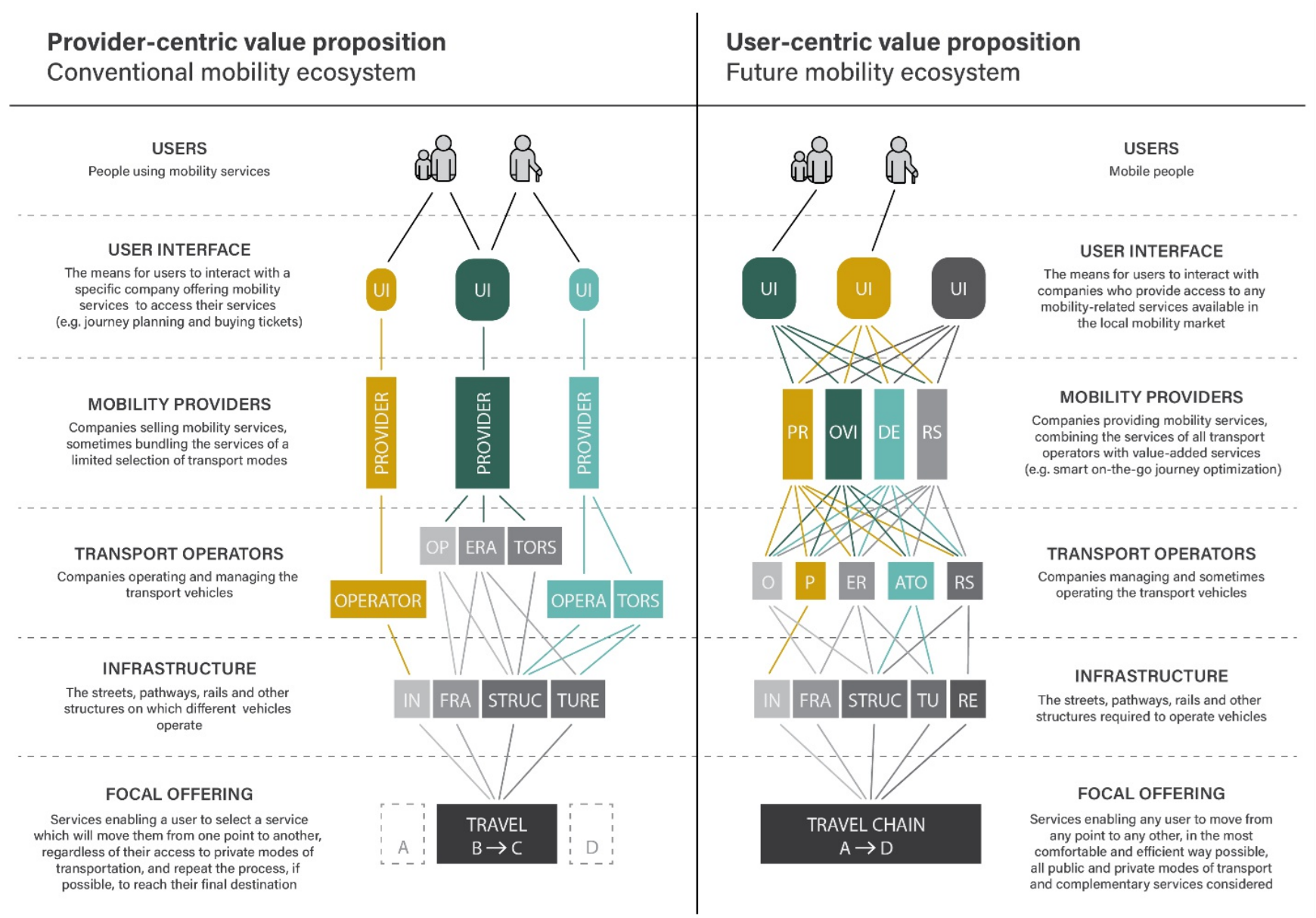

Figure 1. Illustration of the difference in how users access value propositions offered in a conventional mobility ecosystem (left) compared to a future MaaS ecosystem (right). The purpose of the illustrated service chain is to enable users (top) to travel from one point to another. The layers in between represent the chain of functional levels that users are in direct contact with when accessing the service's value proposition. The colors signify single actors, often engaged on several functional levels.

provider is simply travel from point B to C, which constitutes only one part of the entire door-to-door journey typically traveled. However, the customer most often needs to interact with multiple providers and operators on a longer journey, by repeating the process of accessing information, buying tickets, and using a physical transport service.

On the right-hand side, the same setting is portrayed in a MaaS environment. While the underlying structure might be much more complex, the user interface may still appear simpler and easier to use because it builds on modular and complementary offerings. Since the value proposition is not a single trip but rather the whole travel chain, the customer might only interact with one party to plan, purchase, and access mobility. Such implementation requires efficient means for simultaneously exchanging data between multiple actors and, therefore, relies on common application programming interface (API) standards to provide the complete service to users. As such, the VP of a MaaS operator (who provides a bundle of services to the end user) defines the focal offering of an emergent ecosystem (Adner, 2017; Kapoor, 2018).

The technological infrastructure for MaaS enables new complementary offerings from external stakeholders (Teece, 2018). While this creates multiple opportunities 


\section{Managing the Disruption of Mobility Services: How to align the value propositions of key ecosystem players Joel Wolff and Esko Hakanen}

to improve the VP for customers (Bailetti et al., 2020), it also increases the setting's complexity, as the boundaries, roles, and responsibilities between the different elements become unclear (Massa et al., 2018). Also, in the urban mobility context, the investments typically rely on public funding, the incumbent operators may be publicly subsidized organizations, and the actions are often shaped by intricated legislation and regulation. Due to these complexities, MaaS implementation requires a careful reconsideration of multiple elements associated with the design of a socio-technical system.

\section{Designing a controlled disruption of the mobility ecosystem}

In the past decade, design practice and research have gained popularity in modeling socio-technical systems and transition processes to support local governance (Hyysalo et al., 2019; Whicher \& Crick, 2019). By definition, socio-technical change involves interrelated changes to existing technologies, structures, tasks, and people (Leavitt, 1964), which in recent years has often been sparked by the advent of new digital technologies (Tilson et al., 2010; Nambisan, 2017). Design research has shown that co-design is an effective way to increase coherence among multiple, interrelated components, as well as multiple stakeholders (Hyysalo et al., 2019). The co-design process is often facilitated through intermediate designs (for example, design games, workshops, and other models) that guide ideation and analysis among divergent participant perspectives to solve high complexity challenges. The purpose of these intermediate designs is not to provide a complete solution, but rather to support complex problem solving through multiple rounds of iterations (Koskinen et al., 2011; Hyysalo et al., 2019). These iterations help to understand different systemic constraints and influences, as well as appreciate the design task simultaneously as a process and outcome (Garud et al., 2008).

The MaaS concept is associated with the disruption of the current mobility market (Hensher et al., 2020). Like any disruptive technology, it faces conflicting interests and attempts to retain the status quo in the market (Adner \& Kapoor, 2016). Similarly, local authorities face the dual problem of keeping conventional mobility services fully operational, while at the same time actively opening the market to greater competition to facilitate new services and operators. As regulative authorities, they are adamant about retaining control of the system, while facing the challenge of disrupting the socio-technical regime without shifting the locus of power. Some provisional ideas have been presented (MaaS Alliance, 2017; Hensher et al., 2020; Smith et al., 2020), but many unresolved questions remain on how MaaS should be designed, supported, and regulated.

\section{Research method and process for constructing an intermediate design}

This research derives from an iterative constructive design research process (Koskinen et al., 2011), supported by qualitative data collection and analysis (Ketokivi \& Choi, 2014). The primary data collection was conducted among officials of local authorities in four major cities across Europe, which we from now on refer to as South, West, Central, and North. Also, representatives of governmental organizations and a leading provider of multimodal Maas solutions, experienced in developing regulations operations for one of the cities, were interviewed to gain an in-depth view of needs from the supplier's and local government's points of view. These data were used in an iterative design process to develop an intermediate design applicable to enabling the emergence of a local MaaS ecosystem (see Hyysalo et al., 2019). Additionally, the iteration enabled abductive analysis of the data (Dubois \& Gadde, 2002, 2014) aimed at theory elaboration (Ketokivi \& Choi, 2014). The work conducted led to a framework that could be used by governing authorities to enable the development of efficient MaaS services within their local or regional markets.

\section{Design as a qualitative research method}

Research related to any form of design can be described as "design research" (Muratovski, 2016). The purpose of constructive design research (CDR) is often to construct something tangible (Koskinen et al., 2011). In this research, the tangible construction was an artifact to be used in a real-life situation with local authorities to support decision-making for regulating MaaS. Accordingly, in CDR, the "construction - be it product, system, space or media-takes center place and becomes the key means in constructing knowledge" (Koskinen et al., 2011). Thus, the researchers' design iterations influence the process, questions, and knowledge that can be attained in the data collection and emphasizes the interaction between the researcher and the user (Whicher \& Crick, 2019). 


\section{Managing the Disruption of Mobility Services: How to align the value propositions of key ecosystem players Joel Wolff and Esko Hakanen}

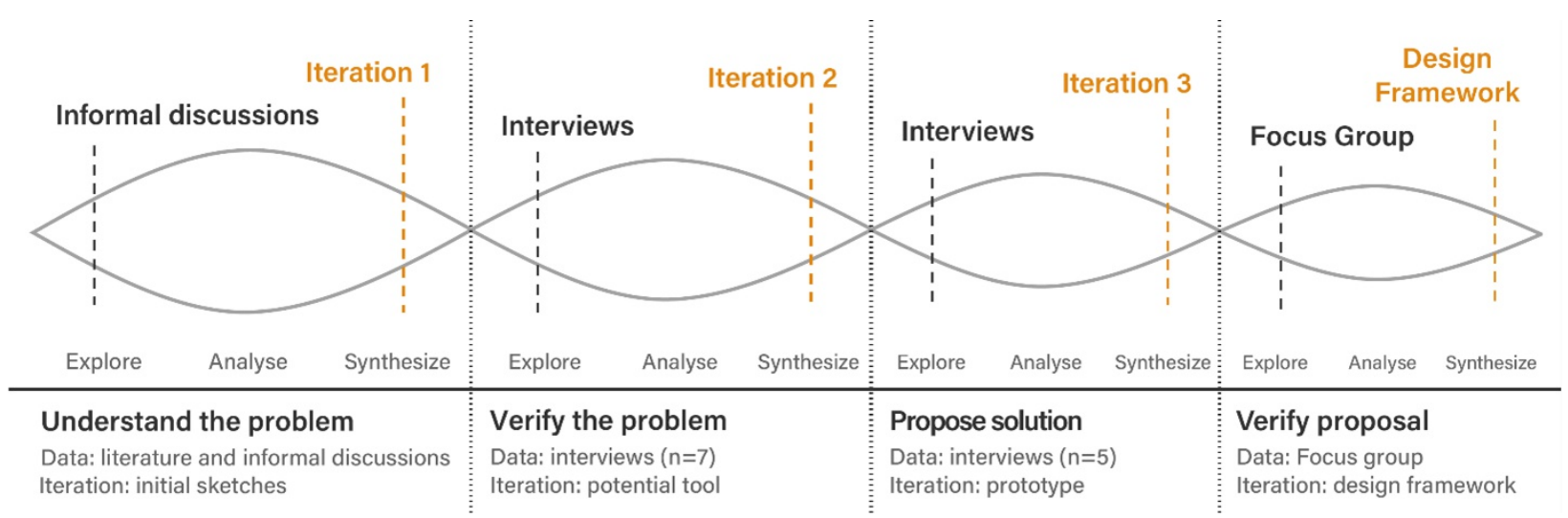

Figure 2. The iterative research process visualized in a simplified diagram to highlight divergent (field expanding) and convergent (field shrinking) thinking being dominant in specific parts of the iterative cycles. The segments of data collection are marked in dark green, while the iterations marked in orange are shown in Figure 3.

This design research process can be summarized in four significant segments of iterative progress, presented in Figure 2. The approach is an adaptation of the Double Diamond model, which illustrates a combination of divergent and convergent thinking as cycles of collecting and analyzing data, followed by directing the collected insights towards creating a solution (Design Council, 2007). The process resembles abductive data analysis principles that combine inductive and deductive reasoning through constant comparison of the accumulating empirical observations and the emerging theoretical framework (Dubois \& Gadde, 2002, 2014).

\section{Data collection and analysis}

Our data collection followed the four stages illustrated in Figure 2. The research process began with informal discussions among key stakeholders and potential users of the resulting intermediate design. Such data collection is instrumental at the beginning of the design process to identify previously unidentified opportunities and refine the design hypothesis once the designer begins to comprehend what should be designed (Portigal, 2013). Subsequent data collection included semi-structured interviews with officials from different local authorities in four major cities across Europe (South, West, Central, and North), conducted in April and May $2020 \quad(n=7)$. At this stage, the informants were civil servants, business representatives, and researchers, all of whom have participated in the development or study of MaaS services across Europe. The second round of interviews was conducted from June to August $2020(n=5)$ with experts from governmental organizations that regulate MaaS and a private organization that provides MaaS services in one of the cities (North) to get an in-depth view of MaaS developments in a local context and from a provider's perspective.

The last stage of the design research process involved a focus group discussion in September 2020 to test the latest iteration of the design. The discussion was held with experts involved in several MaaS projects around Europe. The focus group method was chosen to enable a more candid discussion and encourage the participants to voice differing opinions (Wilkinson, 2004). The focus groups were held online, raising specific challenges, but also possibilities, such as greater participant convenience, or a sense of user anonymity (Stewart \& Shamdasani, 2017). Following the feedback gained in the focus group, our designed framework was simplified and focused on the main setup. The findings from the analysis and subsequent design process follow next.

\section{Summary of key insights derived from the constructive design research process}

This research utilized an iterative design process where data were collected and analyzed at different stages during the project, as presented in Figure 2. Each bundle of data provided new findings, which contributed to show both a direction for reiterating designs and new questions to answer. The key findings that guided the design process will be presented correspondingly. Figure 3 illustrates the three iterations resulting from findings 


\section{Managing the Disruption of Mobility Services: How to align the value propositions of key ecosystem players Joel Wolff and Esko Hakanen}

that arose during the design process (previously demonstrated in Figure 2).

First, the informal discussions indicated that local authorities were struggling to see the big picture of the MaaS value proposition and therefore tended to jump ahead of developments. In their effort to iron out precise details and needs, authorities often failed to recognize the broader implications of MaaS on the mobility ecosystem. These findings supported the initial assumption that a co-design method would be needed to guide local authorities in enabling MaaS in their local region. Gamified workshop tools (1st iteration in Figure 3) were ideated to provide a rough starting point for iterating a suitable method.

The interviews with city officials confirmed that the design method needs to accommodate drastically different challenges in different cities, based on the specific interests of the authorities and stakeholders, as well as prior activities. However, a few common concerns were shared by most interviewees. First, the need to maintain uninterrupted public transport operations has left little to no room for erroneous trials. Second, investment has been difficult to acquire due to high uncertainty regarding future returns, and the time and effort needed to facilitate the transformation. As a result, sufficient technological enablers in the ecosystem are not yet developed (for example, a common standard for application programming interfaces, APIs) to facilitate the development of modular components, such as buying tickets from multiple vendors for a journey. Third, the respondents felt that current public transportation providers must retain a dominant market position so that authorities maintain sufficient influence on the mobility sector. These findings indicate the need to agree and commit to a common cause among all stakeholders, although the question of funding remains unanswered. The second iteration (see Figure 3) revolved around building a shared understanding of changes and actions needed on a step by step basis.

The interviews with MaaS experts $\rightarrow$ who mainly operate in the North region - provided a reference point for the 1st iteration: initial sketches

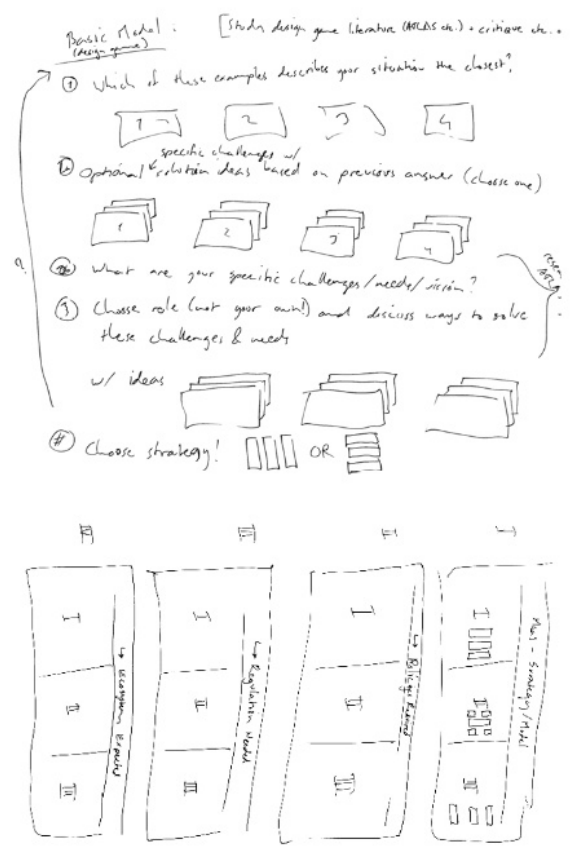

2nd iteration: potential tool

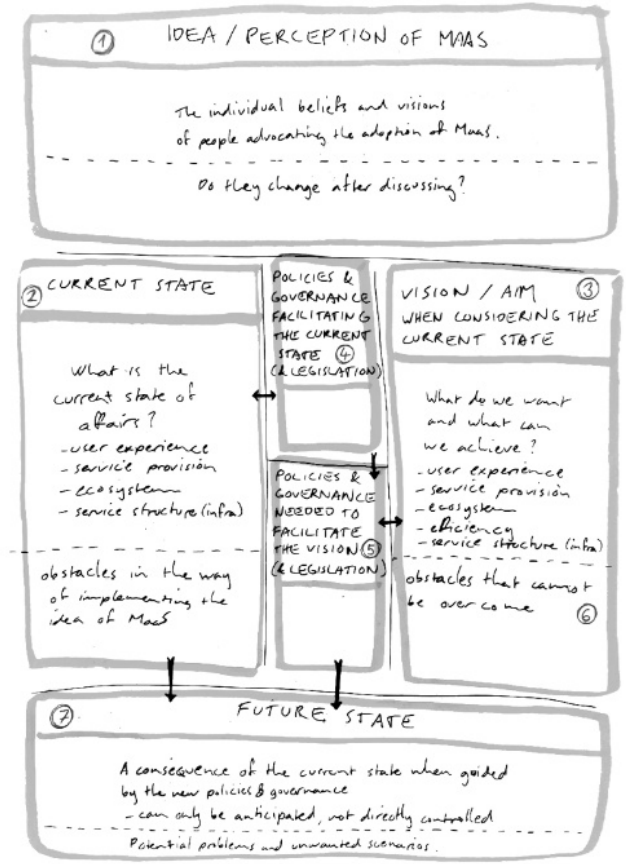

3rd iteration: focus group prototype

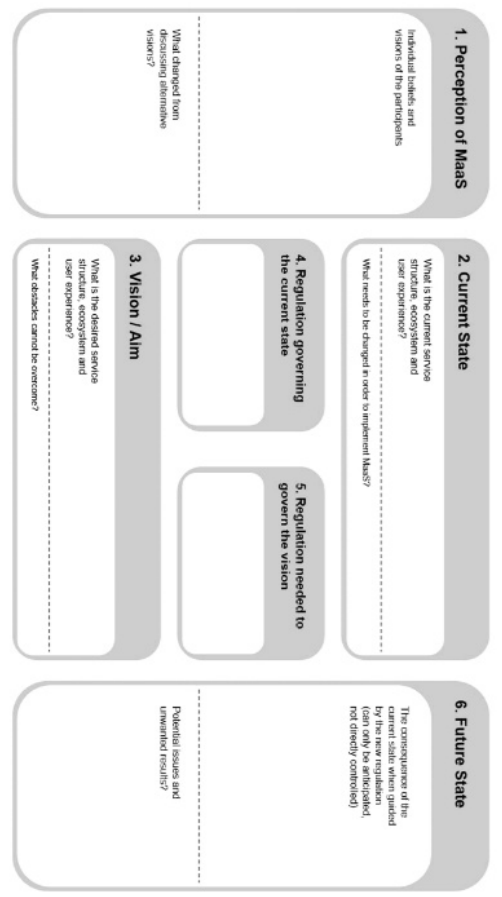

Figure 3. The most influential iterations at the end of each iterative cycle, as referred to in Figure 2 , showing how the solution emerged in the focus group. 


\section{Managing the Disruption of Mobility Services: How to align the value propositions of key ecosystem players Joel Wolff and Esko Hakanen}

expectations regarding many of these challenges. However, none of the aforementioned challenges received clear answers, while many of them remain despite years of trying to get them to work. Instead, the interviewees added to the list of challenges in three essential areas. First, they showed that regulative attempts to force transformation have been highly inefficient due to the lack of self-interest and motivation among the actors. Instead, the informants highlighted the success of a city that took the opposite approach, relying on voluntary agreements, and achieved far more rapid expansion of MaaS services. Second, the profit margins within the sector have already been cut to a minimum, leaving little room for MaaS operators to compete with current industry prices. Third, existing regulation was to some extent seen as frequently obstructing the introduction of MaaS solutions. The demands to expand and connect to national and international MaaS systems have posed additional regulations on future development at the EU level. Since the MaaS ecosystem lacks a central coordinator, open communication through community seminars and forums was hailed as crucial. The third iteration (see Figure 3) clarified the model based on interviews during this stage.

Finally, the focus group discussion with MaaS experts across Europe revealed three more crucial aspects of enabling MaaS locally. First, the experts considered it vital that MaaS was founded on previously defined, comprehensive guidelines (for example, mobility strategies and policies) to reduce opposition. Second, while detailed mobility affairs in the local region concerning everything from parking policies to taxation regulation - must be addressed separately and comprehensively, they have been overlooked. Third, the importance of regulation to enable MaaS has been overstated. Instead, the main focus should lie in aligning and guiding actions and developments between stakeholders. These findings allow the possibility of reframing the method, in order to introduce the co-design framework, which is presented next.

\section{A co-design framework for MaaS policy development}

The latest iteration of the presented design process is a co-design framework (Table 1). In it, we present five crucial steps for successfully implementing MaaS solutions initiated by a local authority. The sequence is not strict, as depending on the local situation, some steps may already have been targeted, while others may need to be adjusted to fit a previously unexpected context.

This study indicated that successful and rapid MaaS development depends on a motivated local authority to set a shared vision for various stakeholders. The first step therefore focuses on establishing broad interest and political backing for the needed transition. MaaS policies, we believe, should be integrated with broader mobility strategies, such as a sustainable urban mobility plan (Rupprecht Consult, 2019). Ultimately, this step aims to initiate mechanisms to engage multiple stakeholders and value propositions that are align with the shared vision of MaaS (Eggert et al., 2018: Bailetti et al., 2020).

Once a shared vision of future mobility services has been agreed upon, the second step evaluates preparedness for rapid MaaS adoption. Measures to deliver this include current infrastructure, available mobility services, parking policies, and transport provider willingness to collaborate. Existing tools useful for this stage may be the MaaS Readiness Level Indicators (Aaltonen, 2017) and MaaS Maturity Index (Goulding \& Kamargianni, 2018). Mapping current actors and offered services provides an outlook of available resources and offerings in the ecosystem (Eggert et al., 2018), thereby facilitating new value propositions that link members directly to the shared vision.

The third step dissects the role of a local authority in enabling MaaS. Since value propositions are vital for facilitating investments and business transactions with external stakeholders (Bailetti et al., 2020), the MaaS strategy and preparedness are utilized to guide dialogue with relevant stakeholders. The goal is to define the role of relevant authorities in enabling the transition. The guided emergence of an ecosystem that can generate competitive MaaS services often depends on some changes to legislation and mutual agreements between partners involved. While ecosystems arise without the "grand designs of business leaders" (Shipilov \& Gawer, 2020), policy decisions regarding MaaS often reflect the local administrative culture and willingness to collaborate among actors in the mobility ecosystem. Examples of tools that can assist in this type of work include the policy framework by Smith (2020) and studies on market access and competition in MaaS (VVA, 2019). 


\section{Managing the Disruption of Mobility Services: How to align the value propositions of key ecosystem players Joel Wolff and Esko Hakanen}

Table 1. MaaS co-design framework intended to guide local authorities to co-creatively enable an efficient adoption of future mobility solutions in the local region.

\begin{tabular}{|c|c|c|c|c|c|}
\hline Sequence & 1 Strategy & 2 Preparedness & 3 Policies & 4 Actions & 5 Management \\
\hline Purpose & $\begin{array}{l}\text { Define how } \\
\text { MaaS ties into } \\
\text { the current } \\
\text { urban mobility } \\
\text { strategy and } \\
\text { how the } \\
\text { desired MaaS } \\
\text { should function. }\end{array}$ & $\begin{array}{l}\text { Measure the } \\
\text { compatibility of } \\
\text { current urban } \\
\text { mobility to the } \\
\text { requirements of } \\
\text { the envisioned } \\
\text { MaaS. }\end{array}$ & $\begin{array}{l}\text { Define how local } \\
\text { mobility should } \\
\text { be governed and } \\
\text { what changes } \\
\text { are needed to } \\
\text { current } \\
\text { regulation } \\
\text { regarding areas } \\
\text { such as mobility, } \\
\text { business, and } \\
\text { taxes. }\end{array}$ & $\begin{array}{l}\text { Define what } \\
\text { actions are } \\
\text { needed to } \\
\text { achieve the goals } \\
\text { previously } \\
\text { defined. Define } \\
\text { how the process } \\
\text { should be } \\
\text { supported and } \\
\text { measured. }\end{array}$ & $\begin{array}{l}\text { Define how the } \\
\text { process is } \\
\text { managed and the } \\
\text { performance } \\
\text { measured on a } \\
\text { timely basis. }\end{array}$ \\
\hline $\begin{array}{l}\text { Examples of } \\
\text { existing } \\
\text { tools }\end{array}$ & $\begin{array}{l}\text { Sustainable } \\
\text { Urban Mobility } \\
\text { Plan }^{1}\end{array}$ & $\begin{array}{l}\text { MaaS Readiness } \\
\text { Level } \\
\text { Indicators }^{2} \text {, } \\
\text { MaaS Maturity } \\
\text { Index }^{3}\end{array}$ & $\begin{array}{l}\text { Policy } \\
\text { framework }{ }^{4} \text { by } \\
\text { Smith }(2020), \\
\text { MaaS } \\
\text { development } \\
\text { models }^{5}\end{array}$ & $\mathrm{~N} / \mathrm{A}$ & $\mathrm{N} / \mathrm{A}$ \\
\hline $\begin{array}{l}\text { Role in } \\
\text { the value } \\
\text { proposition } \\
\text { alignment }\end{array}$ & $\begin{array}{l}\text { Creating a } \\
\text { shared vision } \\
\text { among the } \\
\text { multiple } \\
\text { stakeholders. }\end{array}$ & $\begin{array}{l}\text { Mapping current } \\
\text { actors and } \\
\text { services to align } \\
\text { these with the } \\
\text { shared vision. }\end{array}$ & $\begin{array}{l}\text { Identifying the } \\
\text { role of } \\
\text { authorities as an } \\
\text { external } \\
\text { stakeholder } \\
\text { guiding the } \\
\text { actions. }\end{array}$ & $\begin{array}{l}\text { Establishing } \\
\text { interaction rules } \\
\text { for business } \\
\text { transactions to } \\
\text { attract } \\
\text { complementary } \\
\text { investments. }\end{array}$ & $\begin{array}{l}\text { Forming } \\
\text { common targets } \\
\text { and KPIs for } \\
\text { implementing } \\
\text { the shared } \\
\text { vision. }\end{array}$ \\
\hline
\end{tabular}

Citations:

1 (Rupprecht Consult, 2019); 2 (Aaltonen, 2017); 3 (Goulding \& Kamargianni, 2018); 4 (Smith, 2020); 5 (VVA, 2017)

The fourth step focuses on defining concrete actions and measures needed to achieve desired results. The measures go beyond regulatory incentives (for example, developing technologies, forming collective agreements, and attracting required investments). The purpose is to identify potential technological bottlenecks to enable members' compliance towards swift ecosystem expansion (Adner \& Kapoor, 2016), while ensuring that external stakeholders can contribute to the ecosystem's user value proposition (Eggert et al., 2018; Kapoor, 2018).

A last step is needed to achieve the defined target and ensure that the required development keeps progressing. Ecosystem development requires modular offerings and aligned investments (Jacobides et al., 2018) that facilitate the discreet actions needed to realize an ecosystem's focal offering (Adner, 2017; Kapoor, 2018). It is crucial, therefore, that someone, be it a network or a chosen individual, is focused on overseeing development. By defining key performance indicators, the relevant authorities can measure the progress of ecosystem development and strengthen a collective vision of transformation that also braces to solve future, unforeseen issues.

\section{Elaborating the MaaS ecosystem concept}

The main contribution of this paper has been to clarify the MaaS concept as a complex mobility ecosystem. The envisioned future of MaaS services we presented relies on a focal offering (Adner, 2017; Kapoor, 2018) that enables user-friendly interfaces to access, find, and combine different transport services into a comprehensive, intelligent mobility service system. This vision requires many supporting actions and value propositions by various external stakeholders that need to be aligned accordingly (Eggert et al., 2018; Kapoor, 2018; Bailetti et al., 2020). Rather than offering an entirely new mobility service, MaaS instead provides a 


\section{Managing the Disruption of Mobility Services: How to align the value propositions of key ecosystem players Joel Wolff and Esko Hakanen}

new channel for selling mobility services that can improve the ecosystem's overall efficiency. This setting exhibits challenges that are often associated with advancing general-purpose technologies, such as difficulties in monetization, along with questions on who should lead or pay for development costs (Teece, 2018). Thus, we believe the essential value proposition of a MaaS provider should be to align external, dispersed value propositions from multiple stakeholders into one clearly defined offering for users (Bailetti et al., 2020). Figure 1 illustrates this challenge: while people might agree about the main differences between old and new systems (that is, conventional mobility services and future MaaS solutions), there is still no generally agreed upon proper understanding of how to manage transition from old to new.

We also used practical examples provided by the MaaS context to elaborate on theoretical perspectives within the emerging ecosystem literature. To date, ecosystems have been defined through multiple stakeholders' collective vision, referred to as a focal value proposition or offering (Adner, 2017; Kapoor, 2018). Ultimately, an ecosystem becomes tied together by the non-redeployability of the stakeholders' collective investments elsewhere (Jacobides et al., 2018; Shipilov \& Gawer, 2020). Past examples of ecosystem disruption involve strong focal organizations leading the change and often providing the technological platform to attract complementors (Adner \& Kapoor, 2016; Ozalp et al., 2018; Teece, 2018).

The MaaS context provides a contrasting view of these past examples. Organizations leading the change in MaaS are often public authorities who do not provide a hub and spoke platform, or actively lead the development of new technologies. This raises concerns about whether or not they are having sufficient influence on the result. Instead, we suggest that the MaaS context represents a nested ecosystem (Bronfenbrenner, 1979) with complex interacting and overlapping structures. Public authorities set the principles, policies, and rules to guide the structures and the ecosystem's emergence. Interestingly, the city officials and public authorities in our study indicated a fear of being disrupted that is more commonly seen among private organizations (Gans, 2016). This article therefore suggests that the MaaS context can provide a particularly fertile ground for further contributions that can advance ecosystem research.

\section{Conclusion}

This article provided a contrasting overview of the potential structures for offering mobility services, including the value propositions they provide. Figure 1 illustrated future MaaS mobility solutions against more conventional mobility services. This comparison highlighted two things. First, it showed user-centric improvements in user interface and convenience for users. In conventional, provider-centric service transportation models, one access point (referred to as "user interface") usually gives access to a limited number of travel options that fail to cover an entire journey.

In comparison, we highlighted the focal offering of envisioned MaaS solutions to align and connect all attainable forms of mobility, with dispersed VPs of multiple external stakeholders integrated through a single access point. Typically, these are conceived as digital applications, including customizable routeplanning, ticketing, and nimble rerouting, to name a few key functions. Second, it shows how efficiency changes between the two ecosystems. In conventional mobility ecosystems, efficiency has been improved from the provider perspective by bundling certain functions behind single actors within a certain organizational structure or operator. In contrast, future mobility ecosystems aim to optimize efficiency from a user perspective, thus promoting modularity, fragmentation, and complementary market offerings in an open ecosystem.

This study did not address the impact of an ecosystem's focal offering and aligned VPs on scaling the envisioned MaaS mobility ecosystem. As the ecosystem grows and develops through inputs from multiple key players, it calls for an increasingly challenging dynamic configuration of internal and external resources. Thus, we encourage future studies to address issues related to scaling of focal offerings and aligning VPs in digitallydriven MaaS ecosystems.

In addition, the findings showed that local authorities are adamant that they have control over the mobility services market and ecosystem for public transport and will also have it in the future. This requirement may result from the governing authorities' interest in maintaining sufficient control over the mobility services market. However, as technology advances and the 


\section{Managing the Disruption of Mobility Services: How to align the value propositions of key ecosystem players Joel Wolff and Esko Hakanen}

mobility ecosystem changes, so too does the relationships between actors in it, which we believe in the example of MaaS calls for new ways of adopting and practicing control by authorities to manage the imminent disruption.

\section{Acknowledgements}

We would like to thank members of BATCircle (Business Finland) and PRO-MaaS (EIT Urban Mobility, European Institute of Innovation and Technology) for their support. We express our gratitude to the special issue editors Tony Bailetti, Christian Keen and Stoyan Tanev, and managing editor Gregory Sandstrom, for their helpful comments and suggestions for improving the article.

\section{References}

Aaltonen, S. 2017. MaaS Readiness Level Indicators for Local Authorities. Retrieved from: http://civitas.eu/sites/default/files/maas_readiness_ level_indicators_for_local_authorities_web.pdf

Adner, R. 2017. Ecosystem as Structure: An actionable construct for strategy. Journal of Management, 43(1): 39-58.

DOI: https://doi.org/10.1177/0149206316678451

Adner, R., \& Kapoor, R. 2016. Right Tech, Wrong Time. Harvard Business Review, 94(11): 60-67. DOI: https://doi.org/10.1109/emr.2017.8233298

Amit, R., \& Zott, C. 2012. Creating Value Through Business Model Innovation. MIT Sloan Management Review, 53(3): 41-49.

Arias-Molinares, D., \& García-Palomares, J.C. 2020. The Ws of MaaS: Understanding mobility as a service from a literature review. IATSS Research, 44(3): 253263.

DOI: https://doi.org/10.1016/j.iatssr.2020.02.001

Bailetti, T., Keen, C., \& Tanev, S. 2020. Call for PapersAligning Multiple Stakeholder Value Propositions: The challenge of new companies committed to scale early and rapidly. Technology Innovation Management Review, 1-3.

https://timreview.ca/article/1349

Bailetti, T., Tanev, S., \& Keen, C. 2020. What Makes Value Propositions Distinct and Valuable to New Companies Committed To Scale Rapidly? Technology Innovation Management Review, 10(6): 14-27. DOI: https://doi.org/10.22215/timreview/1365

Bronfenbrenner, U. 1979. The Ecology of Human Development: Experiments by Nature and Design. Harvard University Press. DOI: $10.1080 / 00131728109336000$

Christensen, C.M. 1997. The Innovator's Dilemma: When New Technologies Cause Great Firms to Fail. Boston, Massachusetts: Harvard Business School Press.

Christensen, C.M., Raynor, M.E., \& McDonald, R. 2015. What is Disruptive Innovation? Harvard Business Review, 93(12): 44-53.

Design Council. 2007. Eleven Lessons: Managing Design in Eleven Global Brands. London, UK.

Dubois, A., \& Gadde, L.E. 2014. "Systematic Combining"-A decade later. Journal of Business Research, 67(6): 1277-1284. DOI: https://doi.org/10.1016/j.jbusres.2013.03.036

Dubois, A., \& Gadde, L. 2002. Systematic Combining: An abductive approach to case research. Journal of Business Research, 55: 553-560. DOI: https://doi.org/10.1016/S0148-2963(00)00195-8 


\section{Managing the Disruption of Mobility Services: How to align the value propositions of key ecosystem players Joel Wolff and Esko Hakanen}

Eggert, A., Ulaga, W., Frow, P., \& Payne, A. 2018. Conceptualizing and Communicating Value in Business Markets: From value in exchange to value in use. Industrial Marketing Management, 69: 80-90. DOI:

https://doi.org/10.1016/j.indmarman.2018.01.018

European Commission. 2019. Communication from the commission to the European Parliament, the European Council, the European Economic and Social Committee and the Committee of the Regions The European Green Deal.

DOI: https://doi.org/10.2307/j.ctvd1c6zh.7

Gans, J. 2016. The Disruption Dilemma. The MIT Press.

Garud, R., Jain, S., \& Tuertscher, P. 2008. Incomplete by Design and Designing for Incompleteness. Organization Studies, 29(3): 351-371.

DOI: https://doi.org/10.1007/978-3-540-92966-6_7

Goulding, R., \& Kamargianni, M. 2018. The Mobility as a Service Maturity Index: Preparing cities for the mobility as a service era. 7th Transport Research Arena TRA 2018. Vienna, Austria.

Heikkilä, S. 2014. Mobility as a Service - A Proposal for Action for the Public Administration. Aalto University.

Hensher, D.A., Ho, C.Q., Mulley, C., Nelson, J.D., Smith, G., \& Wong, Y.Z. 2020. Understanding Mobility as a Service (MaaS): Past, Present and Future. Amsterdam: Elsevier.

DOI: https://doi.org/10.1016/b978-0-12-8200445.00001-4

Hyysalo, S., Marttila, T., Perikangas, S., \& Auvinen, K. 2019. Codesign for Transitions Governance: A midrange pathway creation toolset for accelerating sociotechnical change. Design Studies, 63: 181-203. DOI: https://doi.org/10.1016/j.destud.2019.05.002

Jacobides, M.G., Cennamo, C., \& Gawer, A. 2018. Towards a Theory of Ecosystems. Strategic Management Journal, 39(8): 2255-2276.

DOI: https://doi.org/10.1002/smj.2904

Kapoor, R. 2018. Ecosystems: Broadening the Locus of Value Creation. Journal of Organization Design, 7(1): 12.

DOI: https://doi.org/10.1186/s41469-018-0035-4

Ketokivi, M., \& Choi, T. 2014. Renaissance of Case Research as a Scientific Method. Journal of Operations Management, 32(5): 232-240.

DOI: https://doi.org/10.1016/j.jom.2014.03.004

Koskinen, I., Zimmerman, J., Binder, T., Redström, J., \& Wensveen, S. 2011. Design Research through Practice: From the Lab, Field, and Showroom. Waltham, MA: Elsevie.

Leavitt, H.J. 1964. Applied Organizational Change in Industry: Structural, Technological and Humanistic Approaches. In J. G. March (Ed.), Handbook of Organizations, 1144-1170. Chicago: Rand McNally \& Company.
MaaS Alliance. 2017. Guidelines \& Recommendations to Create The Foundations for a Thriving Maas Ecosystem. Retrieved from:

https://maas-alliance.eu/wp-

content/uploads/sites/7/2017/09/MaaS-

WhitePaper_final_040917-2.pdf

Massa, L., Viscusi, G., \& Tucci, C. 2018. Business Models and Complexity. Journal of Business Models, 6(1): 59-71.

DOI: https://doi.org/10.5278/ojs.jbm.v6i1.2579

Moore, J.F. 1993. Predators and Prey: A new ecology of competition. Harvard Business Review, 71(3): 75-83.

Muratovski, G. 2016. Research for Designers: A Guide to Methods and Practice. London, UK: SAGE.

Nambisan, S. 2017. Digital Entrepreneurship: Toward a digital technology perspective of entrepreneurship. Entrepreneurship: Theory and Practice, 41(6): 10291055.

DOI: https://doi.org/10.1111/etap.12254

Neely, A. 2008. Exploring the Financial Consequences of the Servitization of Manufacturing. Operations Management Research, 1(2): 103-118.

DOI: https://doi.org/10.1007/s12063-009-0015-5

Ozalp, H., Cennamo, C., \& Gawer, A. 2018. Disruption in Platform-Based Ecosystems. Journal of Management Studies, 55(7): 1203-1241.

DOI: https://doi.org/10.1111/joms.12351

Pangbourne, K., Mladenović, M.N., Stead, D., \& Milakis, D. 2020. Questioning Mobility as a Service: Unanticipated implications for society and governance. Transportation Research Part A, 131: 3549.

DOI: https://doi.org/10.1016/j.tra.2019.09.033

Payne, A., Frow, P., \& Eggert, A. 2017. The Customer Value Proposition: Evolution, development, and application in marketing. Journal of the Academy of Marketing Science, 45(4): 467-489.

DOI: https://doi.org/10.1007/s11747-017-0523-z

Portigal, S. 2013. Interviewing Users: How to Uncover Compelling Insights. New York: Rosenfield Media.

Rajala, R., Hakanen, E., Seppälä, T., Mattila, J., \& Westerlund, M. 2018. How Do Intelligent Goods Shape Closed-Loop Systems? California Management Review, 60(3): 20-44.

DOI: https://doi.org/10.1177/0008125618759685

Rupprecht Consult. 2019. Guidelines - Developing and implementing a sustainable urban mobility plan. Retrieved from:

http://www.eltis.org/sites/eltis/files/sump_guidelin es_en.pdf

Shipilov, A., \& Gawer, A. 2020. Integrating Research on Inter-Organizational Networks and Ecosystems. Academy of Management Annals, 14(1): 92-121. DOI: https://doi.org/10.5465/annals.2018.0121 


\section{Managing the Disruption of Mobility Services: How to align the value propositions of key ecosystem players Joel Wolff and Esko Hakanen}

Smith, G. 2020. Making Mobility-as-a-Service: Towards Governance Principles and Pathways. Chalmers University of Technology.

DOI: https://doi.org/10.1016/j.tranpol.2020.02.004

Smith, G., Sochor, J., \& Karlsson, I.C.M A. 2020. Intermediary MaaS Integrators: A case study on hopes and fears. Transportation Research Part A: Policy and Practice, 131(September 2019): 163-177. DOI: https://doi.org/10.1016/j.tra.2019.09.024

Snihur, Y., Thomas, L.D.W., \& Burgelman, R.A. 2018. An Ecosystem-Level Process Model of Business Model Disruption: The disruptor's gambit. Journal of Management Studies, 55(7): 1278-1316.

DOI: https://doi.org/10.1111/joms.12343

Stewart, D.W., \& Shamdasani, P. 2017. Online Focus Groups. Journal of Advertising, 46(1): 48-60. DOI: https://doi.org/10.1080/00913367.2016.1252288

Teece, D.J. 2018. Profiting from Innovation in the Digital Economy: Enabling technologies, standards, and licensing models in the wireless world. Research Policy, 47: 1367-1387.

DOI: https://doi.org/10.1016/j.respol.2017.01.015

Tilson, D., Lyytinen, K., \& Sørensen, C. 2010. Research Commentary-Digital Infrastructures: the missing IS research agenda. Information Systems Research, 21(4): 748-759.

DOI: https://doi.org/10.1287/isre.1100.0318

Venters, W., \& Whitley, E.A. 2012. A Critical Review of Cloud Computing: Researching desires and realities. Journal of Information Technology, 27(3): 179-197. DOI: https://doi.org/10.1057/jit.2012.17

VVA. 2019. Study on market access and competition issues related to MaaS. Milan.

Whicher, A., \& Crick, T. 2019. Co-design, Evaluation and the Northern Ireland Innovation Lab. Public Money and Management, 39(4): 290-299.

DOI:

https://doi.org/10.1080/09540962.2019.1592920

Wilkinson, S. 2004. Focus Group Research. In D. Silverman (Ed.), Qualitative Research: Theory, Method, and Practice, 2nd ed., London: SAGE: 177185.

\begin{abstract}
About the Authors
Joel Wolff, MA (Art \& Design), is a strategic service designer and researcher currently focusing on usercentric sustainable development, systems analysis and urban transformation. His forte is in applying co-creative design methods to facilitate sensemaking and strategy development. Mr. Wolff is affiliated with the Department of Industrial Engineering and the Department of Design at Aalto University.

Esko Hakanen, DSc (Tech), is a postdoctoral researcher in the areas of digitalization, platforms, and value creation and sharing in networks. His work builds on an interdisciplinary background and combines multiple perspectives for analyzing digital transformation as a socio-technical change. Dr. Hakanen is affiliated with the Department of Industrial Engineering and the Design Factory at Aalto University.
\end{abstract}

Citation: Wolff, J. and Hakanen, E. 2021. Managing the Disruption of Mobility Services: How to align the value propositions of key ecosystem players. Technology Innovation Management Review, 11(4): 13-25.

http://doi.org/10.22215/timreview/1433

(cc) BY

Keywords: Mobility-as-a-Service (MaaS), Ecosystem, Value Proposition, Design Framework, Urban Mobility 